\title{
Histological Study of the Sex-Change in the Skunk Clownfish Amphiprion akallopisos
}

\author{
Margarida Casadevall ${ }^{1, *}$, Eulalia Delgado ${ }^{1}$, Orphal Colleye ${ }^{2}$, Samuel Ber Monserrat ${ }^{2}$ and Eric \\ Parmentier $^{2}$ \\ ${ }^{1}$ Environmental Sciences Department, Sciences Faculty, Girona University, 17071 Girona, Spain \\ ${ }^{2}$ Laboratoire de Morphologie Fonctionnelle et Evolutive, Institut de Chimie, Bâtiment B6c, Université de Liège, 4000 \\ Liège, Belgium
}

\begin{abstract}
Sex change in the protandrous fish Amphiprion akallopisos Bleeker, 1853 (F.Pomacentridae) has been analysed. Experiments consisted of placing males together after being separated from their mates, and observe changes in gonad histology at different periods, in order to identify signs of the sex change process. The presence of a first invagination on the male gonad wall, and the observation of the first cortical alveoli oocytes as an indication of the beginning of the vitellogenesis process, was the first symptom of the sex change, which has been detected after 18 days in one of the males. Period needed for the sex changing process was size independent. The process by which wall invagination is converted into ovarian lumen in the future mature ovary is also described.
\end{abstract}

\section{INTRODUCTION}

Anemonefish (Amphiprioninae, Pomacentridae) form social units composed of a breeding pair and several nonbreeders $[1,2]$. Within each group there is a size-based dominance hierarchy: the female is largest, the male is second largest and the non-breeders get progressively smaller as the hierarchy is descended [3-5]. The breeding male prevents all others from mating with the functional female. However, if the female of a group dies, two phenomena can occur: i) the dominant male can migrate to another territory and try to be adopted by another female [6]; and ii) the male changes sex, grows and becomes the breeding female, while the largest non-breeder grows and becomes the breeding male [1,79]. The primary determinants of the sex-change mechanisms appear to be the social organization and the mating system. In clownfish, the largest individual of the dominant sex (i.e. the female) controls the sex change $[10,11]$. This inhibition system is called the protandrous suppression [12]. The mechanism, however, is still unknown. It could be due to pheromones or to the establishment of aggressive behaviour by females towards males $[10,12,13]$. Depending on the species, the duration of the sex modification lasts about 45 days $[8,14]$. This short duration could be due to the competition between different males, and appears to depend on the interaction between conspecifics $[8,12]$.

Six gonadal phases were described on the basis of histological studies $[3,10,15]$ :

- Gonad in immature juveniles, having nonfunctional testicular tissue and predominant ovarian tissue with primary oocytes.

\footnotetext{
*Address correspondence to this author at the Environmental Sciences Department, Sciences Faculty, Girona University, 17071 Girona, Spain; Tel: 003472418498; Fax: 003472418150;

E-mail: margarida.casadevall@udg.edu
}

- Subadult gonads having some functional spermatocysts and primary growth phase oocytes without discernable ovarian lamellae.

- Mature male gonads possess an ovotestis in which mature testicular tissue in various stages and immature ovarian tissue (with oogonia and previtellogenic tissue) are both present.

- During sex change, testicular tissue degenerates and presents a high amount of spermatozoids. The ovarian tissue develops and is full of previtellogenic oocytes.

- Premature females possess an ovarian tissue with oocytes at different stages (until the perinucleolar stage) whereas the testicular region is small and non-functional.

Functional females possess oocytes in all stages of maturity whereas the testicular part is reduced to a narrow band of degenerated tissue surrounding the gonads. In A. melanopus males, oocytes in the early stages of development form a layer of two to three cells thick around a prominent central lumen in the rostral part of the gonad. Posteriorly the lumen opens and the gonadal lobes are medial bands of spermatogenic tissue and lateral bands of oogenic tissue [10]. However, [3] associate the presence of a lumen with the pre-ripe female phase, and not in the ripe male phase in Amphiprion clarkii. With or without the presence of the lumen, the male tissue is mature in both cases, and the female tissue is not. The question is to know if the presence of the lumen can be considered a marker of sex change. In this study, pairs of males were kept for various periods in the same tank in order to observe and describe changes in the gonads related to the Amphiprion akallopisos sex change process. 
Table 1. Sex and Size of the Individuals Analysed, and Experiment Duration. IM Immature

\begin{tabular}{|c|c|c|c|c|c|c|c|c|c|c|c|c|c|}
\hline AA & 1 & 2 & 3 & 4 & 5 & 6 & 7 & 8 & 9 & 10 & 11 & 12 & 13 \\
\hline size (mm) & 31 & 47 & 65 & 48 & 67 & 83 & 52 & 51 & 49 & 48 & 54 & 62 & 61 \\
\hline day (s) & 0 & 0 & 0 & 0 & 0 & 0 & 10 & 10 & 10 & 18 & 18 & 21 & 21 \\
\hline
\end{tabular}

\section{MATERIAL AND METHODOLOGY}

Amphiprion akallopisos (AA) were collected by scuba divers in the lagoon in front of the town of Tulear (Mozambique Canal, west coast of Madagascar) in September 2005 and September 2006. Four anemone hosts (Heteractis magnifica) were also carefully removed from their support and placed in a bucket. One immature (AA1) male, three males (AA2, AA3, AA4) and two females (AA5, AA6) were immediately sacrificed and placed in Bouin's fixative solution for future use as histological sections. Other fishes and anemone hosts were stored in a community tank $(3.50 \times 0.7$ $\mathrm{x} 0.2 \mathrm{~m}$ ) with running seawater.

Different males were then placed in tanks $(80 \times 36 \times 30$ $\mathrm{cm}, 27-28^{\circ} \mathrm{C}$ ) having each a specimen of Heteractis magnifica. In the first trial (2005) three males (AA7, AA8, and AA9) were placed together in a tank $(80 \times 36 \times 30 \mathrm{~cm}, 27-$ $28^{\circ} \mathrm{C}$ ) during 10 days (Table 1). In the second trial (2006), two pairs of males (AA10, AA11 and AA12, AA13) were kept in two separate tanks $\left(80 \times 36 \times 30 \mathrm{~cm}, 27-28^{\circ} \mathrm{C}\right)$ during 18 and 21 days (Table 1). In each experiment, the fishes were fed once a day with TetraMin (Tetra Werke, Melle, Germany) fish flakes and the seawater was changed every two days. At the end of the experiments, fish were sacrificed in MS-222, measured to the nearest $\mathrm{mm}$ (Table 1) and placed in Bouin's fixative solution. The fishes were then dissected, and gonads were removed and embedded in 2-hydroxyethyl methacrylate (GMA). Serial cross sections (6 - $8 \mu \mathrm{m}$ thick) of the gonads were stained with toluidine blue $(\mathrm{pH} \mathrm{4.4)}$ and with basic fuchsin-methylene blue.

\section{RESULTS}

\section{Histology of Immature Gonad}

The AA1 gonad showed predominant ovarian tissue with primary (perinucleolus) oocytes and did not have functional testicular tissue (Fig. 1a).

\section{Histology of Male Gonad}

The AA2, AA3 and AA4 male gonads presented both ovarian and testicular tissues (Figs. 1b \& c). The ovarian tissue was less predominant and found in the periphery of the gonad without completely surrounding it. Only oocytes in the primary growth phase were observed: oogonia, chromatin-nucleolar and perinucleolar stages.

A larger proportion of mature testicular tissue was present, containing seminiferous tubules. In these tubules, cells in all the different stages of development were organized in cysts and showed synchronous development (Fig. 1c). Upon completion of spermiogenesis, cysts open up and the spermatozoa are discharged into the lobular lumen, from where they head to the sperm duct (Fig. 1b). Each gonad contained a main sperm duct which runs lengthwise along its lateroventral side. Close to this area, full of spermatozoa, blood vessels were observed (Fig. 1c).

\section{Histology of Female Gonad}

The AA5 and AA6 female gonads did not show spermatogenic tissue at all (Fig. 1f). Ovarian tissue was well developed around straight luminal spaces. All the oocyte stages were found: chromatin-nucleolar, perinucleolar, cortical alveoli, vitellogenic stages, mature and atretic oocytes (Fig. 1f). Also postovulatory follicles were observed (POF) which means that a recent spawn has been done.

\section{Experimented Fish}

No changes were observed for the three males (AA7, AA8, and AA9) placed 10 days together in the first tank (experiment 1). All of them showed, at the end of this period, subadult male gonads having all the different stages of cell development, including some spermatozoa, and primary growth phase oocytes without discernable ovarian cavities. For this reason, next year the experiment was repeated and period was lengthened.

This time, in each pair, one of the two males appeared to have begun to change sex (AA11 and AA13), which was not the case for their respective partners (AA10 and AA12). In AA11 (Fig. 1d) and AA13 (Fig. 1e), an invagination of the ovarian tissue leading to a gonad lumen formation was observed; the spermatogenic tissue was distributed in the periphery of the gonad and the ovarian tissue was more prominent and surrounding the central ovarian lumen in progress (Fig. 1d \& e). The ovarian tissue was mainly composed of oocytes in the primary growth phase (oogonia, chromatinnucleolar and perinucleolar stages). However, an additional stage of cortical alveoli oocytes was found in AA13 with lipid drops in their cytoplasm. It was possible to see all the spermatogenic stages (from spermatogonia to spermatozoa) in the testicular tissue. However, there was a particularly high amount of spermatozoa. Another difference between AA11 and AA13 was found at the level of the each tissue portion: the ovarian part was more developed in AA13 than in AA11.

In AA10 and AA12, the central gonadal lumen was not observed at all. The ovarian tissue occupied a part on the periphery and only previtellogenic oocyte stages were found: oogonia, nucleochromatic and perinucleolar oocytes. The male tissue is composed of sexual cells in all the different stages including large amounts of spermatozoa. 
(a)
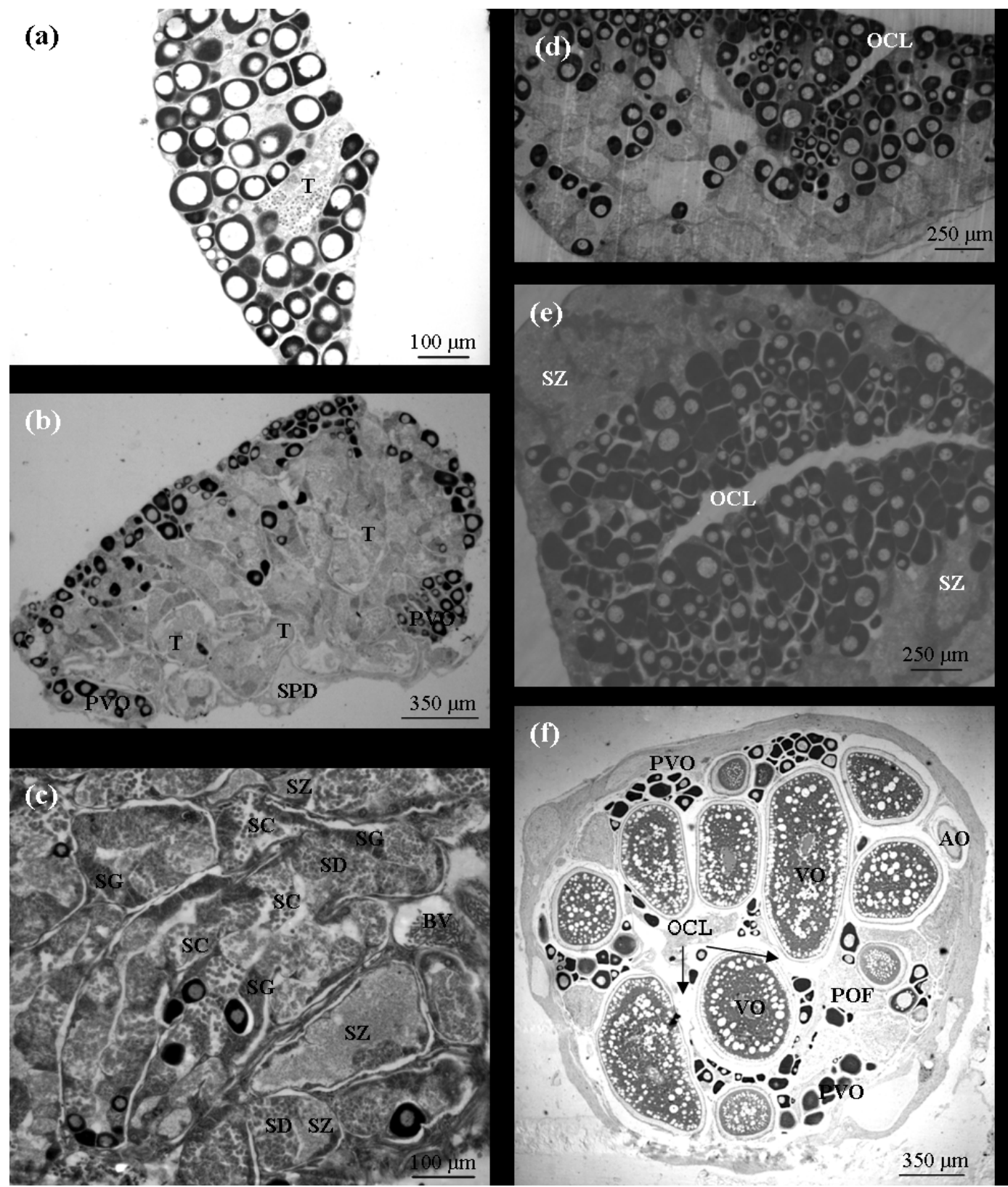

Fig. (1). Amphiprion akallopisos gonads. Transverse section of the immature individual AA1 (a), the mature male AA3 (b, c), and the sexchanging male AA11, with the invagination of the ovarian tissue in progress (d); longitudinal section of the sex-changing male AA13 (e); transverse section of the mature female AA5 (f). AO: Atresic Oocyte; BV: Blood Vessel; OCL: Ovary Central Lumen; PVO: Previtellogenic Oocyte; VO: Vitellogenic Oocyte; POF: Postovulatory Folicle; SC: Spermatocyte; SD: Spermatid; SG: Spermatogonia; SPD: Sperm Duct; SZ: Spermatozoid; T: Testis.

\section{DISCUSSION AND CONCLUSION}

In the mature female, the gonad has an ovarian cavity and different developmental stages of oocytes but the spermatogenic tissue is degenerated [1,3]. All these characteristics are found in females AA5 and AA6. The AA2, AA3, A4, AA10, AA12 fishes are functional males that show all the stages of cell development including spermatozoa. Primary growth oocytes are in the previtellogenic phase [8] and no ovarian cavity is found as was the case for Fricke and Fricke (1977) [16] in a dominant male of A. akallopisos.
Based on our results and data from the literature, a graph summarizing the development of gonads in Amphiprion has been created (Fig. 2).

Cross sections in the gonads were schematized for the three stages (immature, males and females). The process of sex change corresponds to: 1 ) the progressive invagination of the ovarian tissue, leading to the delimitation of a gonad lumen that closes progressively and distributes oocytes on the interior part of the gonad and testicular tissue on the periphery; 2) the degeneration of testicular tissue with a high amount of spermatozoids and progressive loss of all the 


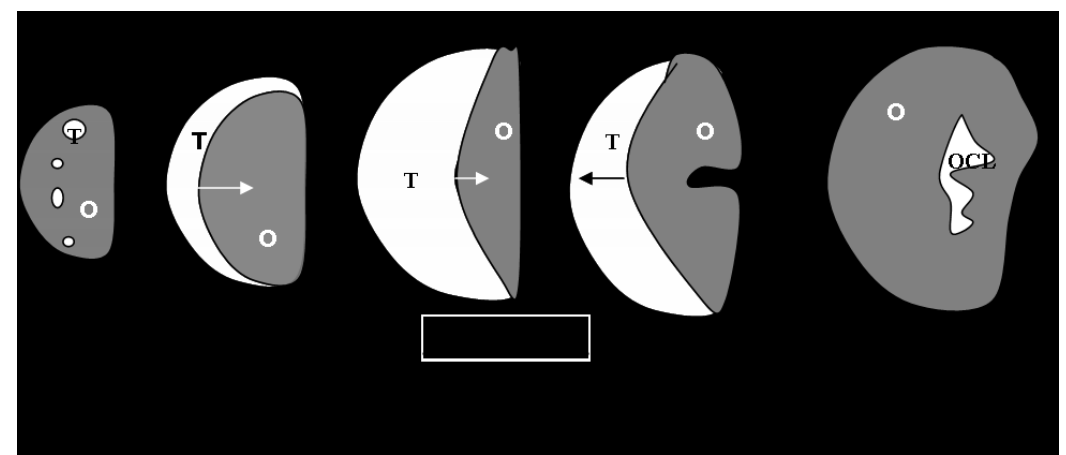

Fig. (2). Schematisation (in transversal section) of the development of gonads from immature to female status in Amphiprion. Metamorphosis corresponds to the sex inversion. O: Ovarian Tissue, OCL: Ovarian Central Lumen; T: Testicular Tissue. (a) Immature Juvenile, (b) subadult male, (c) mature male, (d) sex-change process, (e) functional female.

other stages; and 3) the development of ovarian tissue with previtellogenic oocytes in the first cortical alveoli stages development.

In $A$. akallopisos, the disappearance of the female provokes the metamorphosis of only one of the two males in each experiment The ripe male appears to be the best candidate for metamorphosis, waiting for vacated breeding posts $[9,11]$. We have already verified it when the two males are very different in size. When they are very similar, it is not so evident however. In fact, the male AA13 was rather small than his couple. Anyway, time necessary for the process seems to be independent of the size.

The presence of chromatin-nucleolar and perinucleolar oocytes in males is common, but the observation of the additional cortical alveoli stage in AA13 (after 21 days), indicates that vitellogenesis process is ready to start. Following [17], females should reproduce following the moon cycle, and related to the tides, e.g. every 15 days more or less. It should mean that a period of 15 days is more or less the time needed to complete the second phase growth, the vitellogenesis, in order to prepare a new cluster of cortical alveoli oocytes to the next pond. This result correlates with those of A.melanopus [14]: a drop in 11-KT after 20 days is followed by an ovarian differentiation and an increasing level of oestrogen (estradiol-17 $\beta$ or $\mathrm{E}_{2}$ ).

\section{ACKNOWLEDGEMENTS}

We thank Dra. Marta Muñoz and Dra. Maria Sàbat for their valuable help in the histological work. E.Parmentier is a Research Associate of the Belgian National Fund for Scientific Research (FRS-FNRS). This work was funded by FRSFNRS (FRFC contract no.2.4.583.05).

\section{REFERENCES}

[1] Fricke HW. Mating system, resource defense and sex change in the anemonefish Amphiprion akallopisos. Z Tierpsychol 1979; 50: 313-326.
[2] Fautin DG. Anemonefish recruitment: the roles of order and chance. Symbiosis 1992; 14: 143-60.

[3] Hattori A, Yanagisawa Y. Life-history pathways in relation to gonadal sex differentiation in the anemonefish Amphiprion clarkii in temperate waters of Japan. Environ Biol Fishes 1991; 3: 139155.

[4] Francis RC. Sexual liability in teleosts: developmental factors. Q Rev Biol 1992; 67: 1-18.

[5] Buston PM. Territory inheritance in the clown anemonefish. Proc R Soc Ser B 2004; 271: 252-54

[6] Kuwamura T, Nakashima Y. New aspects of sex change among reef fishes: recent studies in Japan. Environ Biol Fishes 1998; 21: 125-35.

[7] Allen GR. Anemonefishes: Their Classification and Biology. $2^{\text {nd }}$ ed. TFH Publications: Neptune City 1975.

[8] Fricke HW. Social control of sex: field experiments with the anemonefishes Amphiprion bicinctus. Z Tierpsychol 1983; 61: 7177.

[9] Ochi H. Acquisition of breeding space by nonbreeders in the anemonefish Amphiprion clarkii in temperate waters of southern Japan. Ethology 1989; 83: 279-94.

[10] Godwin J. Behavioral aspects of protandrous sex change in the anemonefish, Amphiprion melanopus, and endocrine correlates. Anim Behav 1994; 48: 551-67.

[11] Hattori A. Social and mating systems of the protandrous anemonefish Amphiprion perideraion under the influence of a larger congener. Austra Ecol 2000; 25: 187-92.

[12] Ross RM. The evolution of sex-change mechanisms in fishes. Environ Biol Fishes 1990; 29: 81-93.

[13] Reinboth R. Behavioral aspects of sex inversion in certain fishes. In: Bardach JE, Magnuson JJ, May RC, Reinhart JM, Eds. Proceedings of the 5th ICLARM Conference; Bellagio, Italy: ICLARM; 1980; pp. 271-286.

[14] Godwin JR, Thomas P. Sex change and steroid profiles in the protandrous anemonefish Amphiprion melanopus (Pomacentridae, Teleostei). Genet Comp Endocrinol 1993; 91:144-57.

[15] Yeung WSB, Chan STH. The gonadal anatomy and sexual pattern of the protandrous sex-reversing fish Rhabdosargus sarba (Teleostei: Sparidae). J Zool 1987; 212: 521-532.

[16] Fricke H, Fricke S. Monogamy and sex change by aggressive dominance in coral reef fish. Nature 1977; 266: 830-32.

[17] Gordon AK, Bok A. Frequency and periodicity of spawning in the clownfish Amphiprion akallopisos under aquarium conditions. Aquarium Sci Conserv 2001; 3: 307-13.

This is an open access article licensed under the terms of the Creative Commons Attribution Non-Commercial License (http://creativecommons.org/licenses/by-nc/3.0/) which permits unrestricted, non-commercial use, distribution and reproduction in any medium, provided the work is properly cited. 